\title{
EXPERIMENTAL STUDIES, GEOMETRY ACQUISITION AND GRID GENERATION OF DIESEL ENGINE INLET PORT FOR THREE DIMENSIONAL CALIBRATED CFD CODE FOR FUTURISTIC DESIGN
}

\author{
Shankar. $V^{1}$, Ganesan $V^{2}$, Thejaraju. $\mathrm{R}^{3}$, Varunraju.R $\mathrm{V}^{4}$, Amal Chacko. $\mathrm{K}^{5}$ \& \\ Chakrapani $\mathrm{A}^{6}$ \\ ${ }^{1}$ Professor \& Principal Investigator, ${ }^{2}$ Visiting Professor, ${ }^{3}$ Assistant Professor and \\ Research Faculty , ${ }^{4}$ Research Associate ${ }^{5}$ Fellowship-Student \\ Major Research Project -Diesel Engine Research \& Development \\ Diesel Engine Laboratory \\ Department of Mechanical Engineering, Faculty of Engineering, Christ University \\ Bangalore-560074, India \\ ${ }^{6}$ Operations Manager, Analytical \& Computational Research Inc, Bangalore, India \\ ${ }^{1}$ Email: shankar.v@christuniversity.in
}

\begin{abstract}
A typical diesel engine port is of complicated geometry. This paper addresses the experimental studies of intake port of a four cylinder diesel engine for different vacuum pressures and valve lift positions. In this study the cylinder head is experimented through a paddle wheel flow setup which gives the flow coefficient and swirl number as output. The main scope of the work is to understand the flow behaviour through the intake port and finally to determine mean flow coefficient and mean swirl number for different valve lift ratios $\mathrm{L} / \mathrm{D}$, where $\mathrm{L}$ is valve lift and $\mathrm{D}$ is bore diameter. This paper also addresses the geometry acquisition and grid generation for three dimensional Computational Fluid Analysis for flow filed computation and obtain a calibrated CFD code for future design once the code is validated with experimental results
\end{abstract}

\section{KEYWORDS}

Experimental study, Intake port, mean swirl number, mean flow coefficient, L/D ratio, CFD, calibrated code

\section{BACKGROUND INFORMATION}

The research focus is on diesel engine at Mechanical Engineering Department, Faculty of Engineering Christ University, Bangalore and a research proposal was made [1] and Major Research Project (MRP) and in-house funded project has been sanctioned [2] during November 2013 by the Centre of Research Projects, Christ University for a period of three years. The aim and objective in three phases is a) to create a state-of-the-art facility catering to various class of diesel engines in the range of five to hundred HP. Five to ten HP single cylinder engines are used for irrigation and tiller applications whereas sixty to eighty HP class four cylinder engines are used for light motor vehicle applications, b) to evaluate the base line engine characteristics by extensive testing and endurance testing and c) to work on engine modification by going in for Low Heat Rejection (LHR) engine with the idea of providing value added inputs on the existing engine in terms of better Specific Fuel Consumption (SFC) and reduced pollutants. Research work is in good progress and LHR engine is realized by Thermal Barrier Coating ( TBC) of 
piston crown. A dozen thrust areas are identified for research and one such fascinating area is 3 D Computational Fluid Dynamics (CFD) studies of diesel engine intake port and experimental validation,

Over half a dozen research faculties from various departments - Mechanical, Electrical, Electronics, Mathematics and Chemistry departments participate in this interdisciplinary research program and thirty undergraduate research students participate in the program. The potential spinoff includes: a) faculty pursuing Ph.D. b) Students performing research after prescribed academic hours and turning out project/fellowship reports and c) vendor development for associating with research work. For instance, Amado Tools, Bangalore is involved in fabrication related activities and Automotive Research Association of India (ARAI), Pune is involved in testing at the paddle wheel facility [3].

Shankar [4] gave special lectures on CFD to research students covering two semesters in the academic year 2013-14 and further Analytical Computational Research Inc. , Bangalore headed by Madhukar Rao and team conducted ten months industrial CFD certificate program for research students [5]. Ganesan, retired Professor of Indian Institute of Technology (IIT), Madras delivers special lectures every month on principles of IC ( Internal Engines ) and research on mathematical modelling incorporating inlet swirl, turbulence and combustion analyses [6].

\section{INTRODUCTION}

Research on diesel engine inlet port has been a fascinating area for the last so many decades and continues to be potential area of research in the next generation advanced diesel engines for enhanced mixing and combustion efficiency. There is a need to press into service available tools like Computational Fluid Dynamics (CFD) which is far advanced in terms of millions of grids coupled with a potential solver. The 3 Dimensional (D) CFD analysis, no doubt, gives a lot of information. However, testing is required to calibrate the CFD code so that it would be useful for future design, development and optimization of inlet ports. This, in turn, has a tremendous effect on power, Specific Fuel Consumption (SFC) and exhaust emissions from the engine. CFD has minimized testing efforts; however it does not and cannot eliminate experimental tests. S.K Sabale and S.B. Sanab [7] has developed a methodology for design of helical inlet port targeting high swirl number of the order of 1.8 and experimentally tested in paddle wheel facility. .

Anqi Chen [8] gives a mathematical description and numerical approximation of the flow through inlet port and uses STAR CD CFD code for 3 D CFD analysis. Steady flow in the inlet port and the cylinder is analysed and computation of unsteady flow is highlighted. . Researchers in the past used classical diagnostic techniques, such as hot wire anemometer [9], to investigate engine flow field. For the analytical work, method of characteristics [10] has been used for computation. With the advancement of both software and hardware capabilities, powerful 3 D CFD codes like Fluent, Star CD are used for computation optical diagnostics are employed for experimental verification.

It is recognized that volumetric efficiency and therefore power output could be considerably increased by improving air induction and flow characteristics. Air motion into the cylinder during intake stroke of an internal combustion engine is one of the important factors, which govern the performance of an engine. Swirl is the rotation of charge about cylinder axis and it is used in diesel engines to control air-fuel mixing. Several research studies related to swirl enhancement in IC engines reported that swirl facilitates mixing of air fuel mixture and increases the combustion rate. Furthermore, a high swirl is also not desired, as kinetic energy for the flow is obtained at expense of a reduced volumetric efficiency. Optimum swirl can be created by optimum design of the intake port. An optimal swirl ratio is not only good for optimum combustion, but also for optimal emission reduction[11]. The recent experiments and 
computations have indicated that the induction generated turbulence, which independent of its initial magnitude, decays by the time of ignition to levels determined by the engine speed. Therefore, it is desirable for the bulk in-cylinder flow to persist through compression, hence releasing its stored kinetic energy at convenient time for combustion to be affected. The controlling parameter is the design and orientation of intake port, in the absence of piston bowl effects. The significant portion of the combustion process takes place by diffusion of flames in a diesel engine. The air-fuel mixing controls the rate of chemical reaction and hence the heat release under this condition. The earlier studies show that the air-fuel mixing is a function of kinetic energies associated with fuel injection and air turbulence[12].

Yufeng $\mathrm{Li}$ [13] proposed new equations for estimation of swirl ratio in which the volumetric efficiency, the compression ratio and pressure drop through intake valve are taken into consideration. Cylinder head of few diesel engines were tested on the steady flow rig and their swirl ratios were estimated by these methods. However the result did not show much difference but corrections of the compression ratio, the volumetric efficiency and pressure drop on the swirl ratio were clearly understood.

The focus on present work is to experimentally investigate the swirl number and flow coefficient for different valve lift and vacuum pressure. The test article is typical research engine cylinder head of a four cylinder four stroke seventy two HP diesel engine with a bore of the order of 76 $\mathrm{mm}$ and stroke being $80 \mathrm{~mm}$. Ideally, it is good to test all the four ports individually y to have a statistical correlation of data. However, extensive tests are carried out on one port and 3 D CFD analysis is in progress for validation and for future design purposes. The experimental results are presented in RTME International Conference, Dubai, during April 2016 [14] and further published in [15].

Further, attempts are made for geometry acquisition in terms of three dimensional model of a typical diesel engine inlet port, geometry cleaning and grid generation for further three dimensional CFD analysis, experimentally validate and to obtain a calibrated CFD code for futuristic design purposes.

\section{TYPICAL INLET PORT}

A typical intake port geometry and schematic representation of swirl flow behaviour through the intake port is shown in Fig. 1 and a schematic of steady flow swirl is given in Fig. 2.

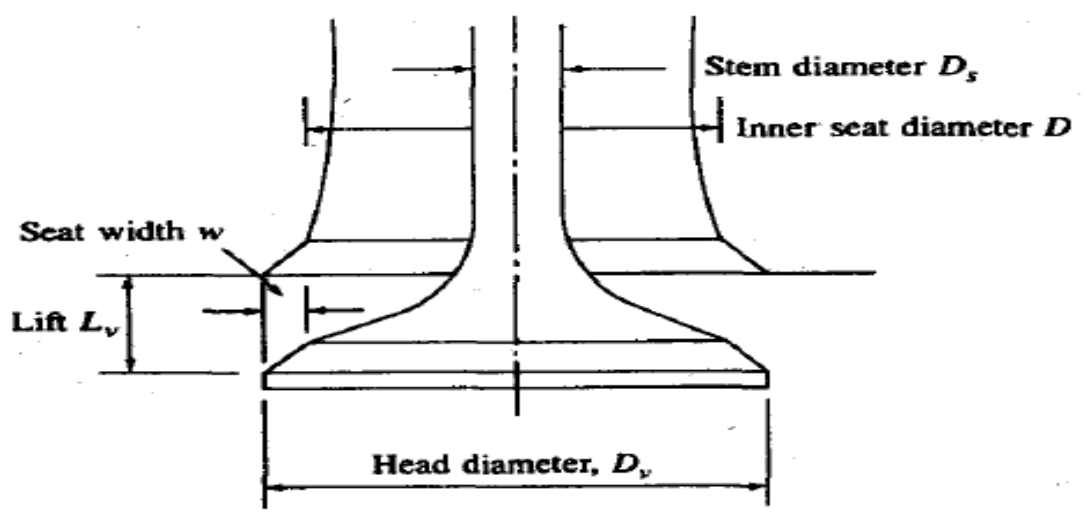

Fig. 1 Typical inlet port and valve assembly 


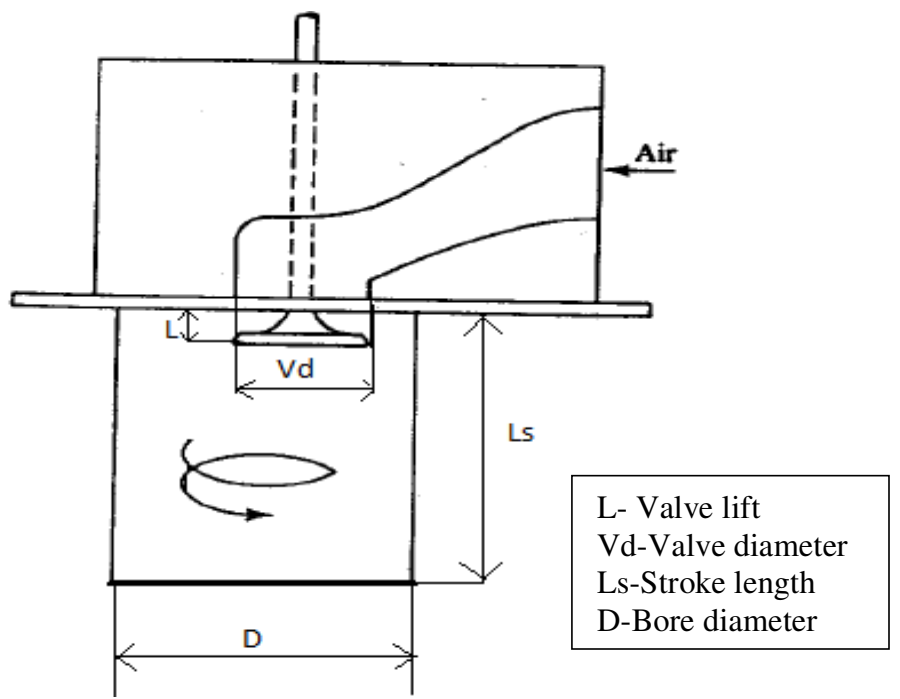

Fig. 2 Schematic of steady flow swirl

\subsection{Parameters Governing Swirl Flow}

It has been observed that in-cylinder flow strongly depends on the inlet port, valve and cylinderhead geometry. Thus in order to better understand the swirl flow behaviour, it is necessary to understand the effect of each design parameters - effect of valve shape, port shape, valve lift and pressure drop on swirl flow.

\subsubsection{Effect of Valve Shape}

In order to understand the effect of valve shape, the fillet radius of the valve stem, angle of valve head, valve seat angle and sharp corners on the valve and seat have been changed and their influence on air flow characteristics was studied by Tanaka[16]. He found that rounding of sharp corners on the valve and the seat had major influence as rounding of corners between valve and seat made convergent-divergent nozzle which increases the air flow rate.

\subsubsection{Effect of Port Shape}

The shape of the port near port exit and passage between valve seat and valve head effects the flow pattern. Flow coefficient defined as ratio of measured flow rate and theoretical flow rate increases when the square ratio of port diameter to valve seat diameter were in range of 2.25 to 4.0 as the resistance to the flow decreases studied by Kastner et al.[17].

\subsubsection{Effect of Valve Lift}

Flow pattern inside the inlet valve and cylinder vary with valve lift. In an automobile engine, the valve lift is limited by getting the valve open and shut quickly and is generally one-fifth of valve head diameter. Khalighi[18] observed that at low lifts, the swirl pattern is characterized by double rotation under the valve and flow remains attached to valve head and seat whereas at higher lifts, there is only single rotation and flow separates from valve head. Hence, the discharge coefficient ,$C_{d}$, decreases at low valve lift and then increases with increase in valve lift.

\subsubsection{Pressure Drop}

Flow through intake valve and its seat is similar to flow through venture in which passage converges and diverges. The discharge coefficient decreases as the pressure drop is increased thus limiting the flow rate of air inside the cylinder. At higher valve lifts, the discharge coefficient is independent of pressure drop as flow breaks away from wall and passage has more divergence. 


\section{TEST PLAN}

To measure the swirl number of the engine under consideration for the following conditions:

a. For various air-flow rate ( with a pressure differential between $200-650 \mathrm{~mm}$ of water)-200, $250,300,350,400,450,500,550,600$ and $650 \mathrm{~mm}$ of water

b. For different intake valve lifts $(0-8 \mathrm{~mm})$

Swirl tests have been carried out in the paddle wheel facility of Automotive Research Association of India (ARAI), Pune. Typical test plan is given in table 1[19,20].

\begin{tabular}{|c|c|c|c|c|c|c|c|c|c|}
\hline \multirow{2}{*}{$\begin{array}{l}\text { SI. } \\
\text { No }\end{array}$} & \multirow{2}{*}{$\begin{array}{l}\text { Pressure } \\
\text { (mm of } \\
\text { Water) }\end{array}$} & \multicolumn{8}{|c|}{ Valve Lift (mm) } \\
\hline & & V1 & V2 & V3 & V4 & V5 & V6 & V7 & V8 \\
\hline 1 & 200 & 8 & 7 & 6 & 5 & 4 & 3 & 2 & 1 \\
\hline 2 & 250 & 8 & 7 & 6 & 5 & 4 & 3 & 2 & 1 \\
\hline 3 & 300 & 8 & 7 & 6 & 5 & 4 & 3 & 2 & 1 \\
\hline 4 & 350 & 8 & 7 & 6 & 5 & 4 & 3 & 2 & 1 \\
\hline 5 & 400 & 8 & 7 & 6 & 5 & 4 & 3 & 2 & 1 \\
\hline 6 & 450 & 8 & 7 & 6 & 5 & 4 & 3 & 2 & 1 \\
\hline 7 & 500 & 8 & 7 & 6 & 5 & 4 & 3 & 2 & 1 \\
\hline 8 & 550 & 8 & 7 & 6 & 5 & 4 & 3 & 2 & 1 \\
\hline 9 & 600 & 8 & 7 & 6 & 5 & 4 & 3 & 2 & 1 \\
\hline 10 & 650 & 8 & 7 & 6 & 5 & 4 & 3 & 2 & 1 \\
\hline
\end{tabular}

Table 1 Intake Port Test Matrix

\section{PADDLE WHEEL SETUP}

The Swirl test facility in ARAI is shown in Fig 3. and a schematic of the test facility is given in Fig 4.

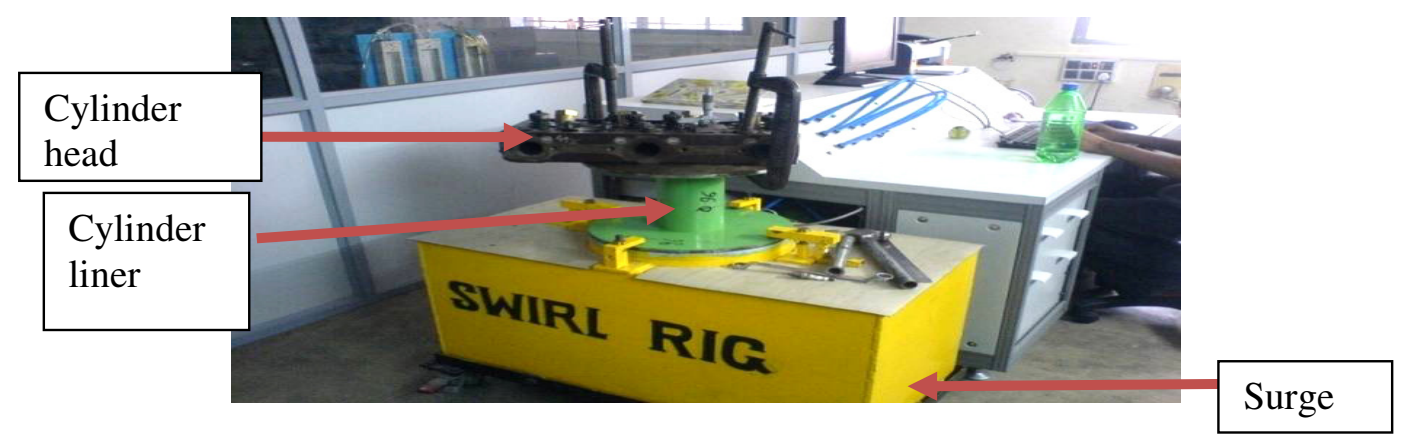

Fig 3. Swirl Flow Rig [3]

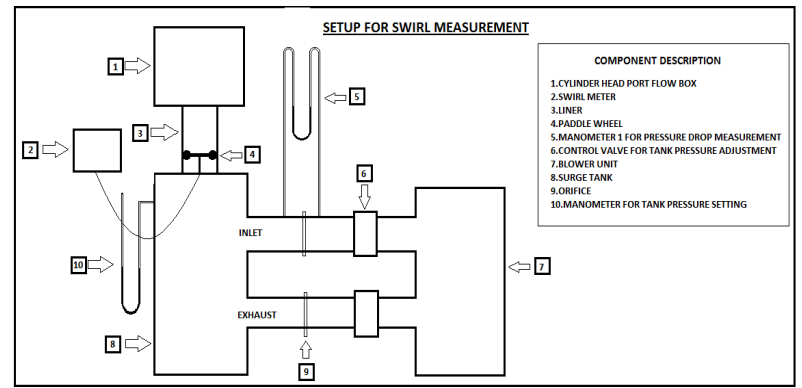

Fig. 4 A Schematic of paddle wheel facility at ARAI, Pune

Air swirl speed or momentum in the cylinder generated by intake ports is generally measured on a steady flow rig. The variable frequency drive blower provides an air flow source for the steady flow rig. The cylinder head to be measured is placed on the rig bench and is centred well with 
cylinder dummy which has diameter identical to engine bore. The steady flow starts from maximum valve lift up to $1 \mathrm{~mm}$ of valve lift.

\section{GEOMETRY ACQUISITION}

The geometry acquisition takes two third of time in any 3 D CFD analysis. Hence, it is worth making a lot of efforts to ensure accuracy at every stage.

\subsection{THREE D MODEL}

A typical model using PRO E software [21] is shown in Fig. 5.

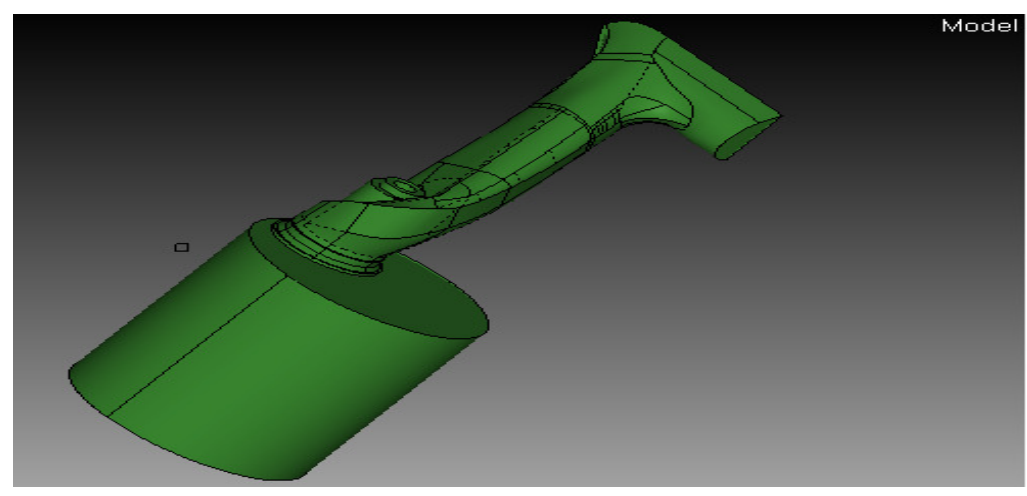

Fig. 5 Three Dimensional of a typical diesel engine inlet port

\subsection{GRID GENERATION}

Meshing is one of the most important tasks in any numerical simulation. Ideally meshing should represent the geometry and physics completely. Even though historically hexahedral elements are preferred over tetrahedral elements to discretize the geometry, tetrahedral elements are the clear choice to discretize the complex geometries of this type. The advantages of using hexahedral elements can be easily offset by increasing the number of tetrahedral elements. In this case, 1 , 33,000 tetrahedral elements are used to discretize the geometry. Mesh sensitivity analysis using at least three different mesh densities will be performed to identify the optimal mesh density while calibrating the code with experiments. A base simulation with the optimised mesh density will be conducted, followed by adaptive local refinement, based on the solution gradients.

Base grid is generated using software [22] and typical grid is shown in Fig. 6.

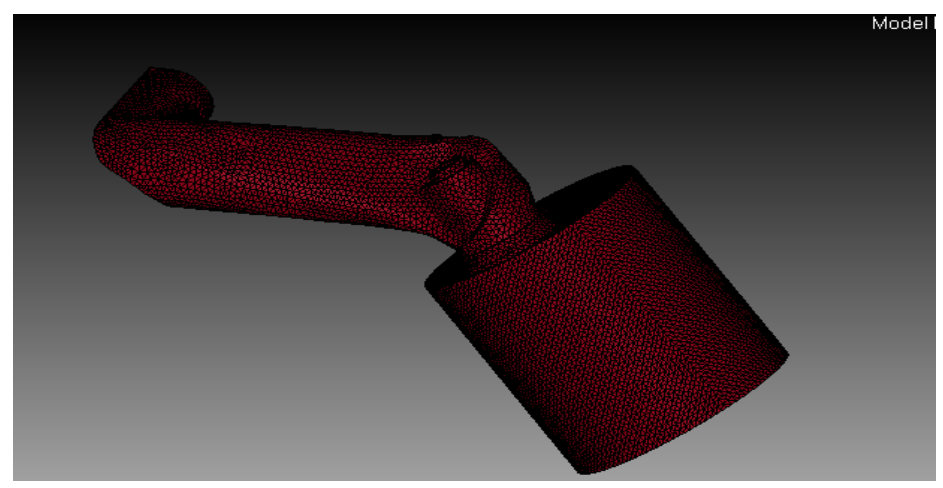

Fig. 6 Grid Generation

\subsection{GOVERNING EQUATIONS AND BOUNDARY CONDITIONS}

The governing equations are continuity, momentum and energy equations supplements by equation of state [23]. 


\subsection{PHYSICAL MODEL OF TURBULENCE}

By default two equation turbulence model is used [23]. Subsequently, it is planned to incorporate three different types of turbulence model when we go in for the calibrated code exercise.

\subsection{SOLVER ANSWER}

ANSWER $^{\circledR}$ has been developed for solution of the Navier-Stokes, the Boundary Layer and the Convective Transport equations including chemical reactions, combustion and turbulence. ANSWER $^{\circledR}$ - General purpose CFD solved developed by ACRi (WWW.ACRiCFD.COM) is used to for the simulations.

\section{RESULTS AND DISCUSSION}

Results and discussion regarding experimental results and grid quality check are presented below:

\subsection{EXPERIMENTAL RESULTS}

The current study involves determination of mean swirl number, mean flow coefficient, paddle wheel speed, and discharge coefficient and flow rate with respect to L/D non dimensional ratio for various pressures. The results are presented and discussed below:

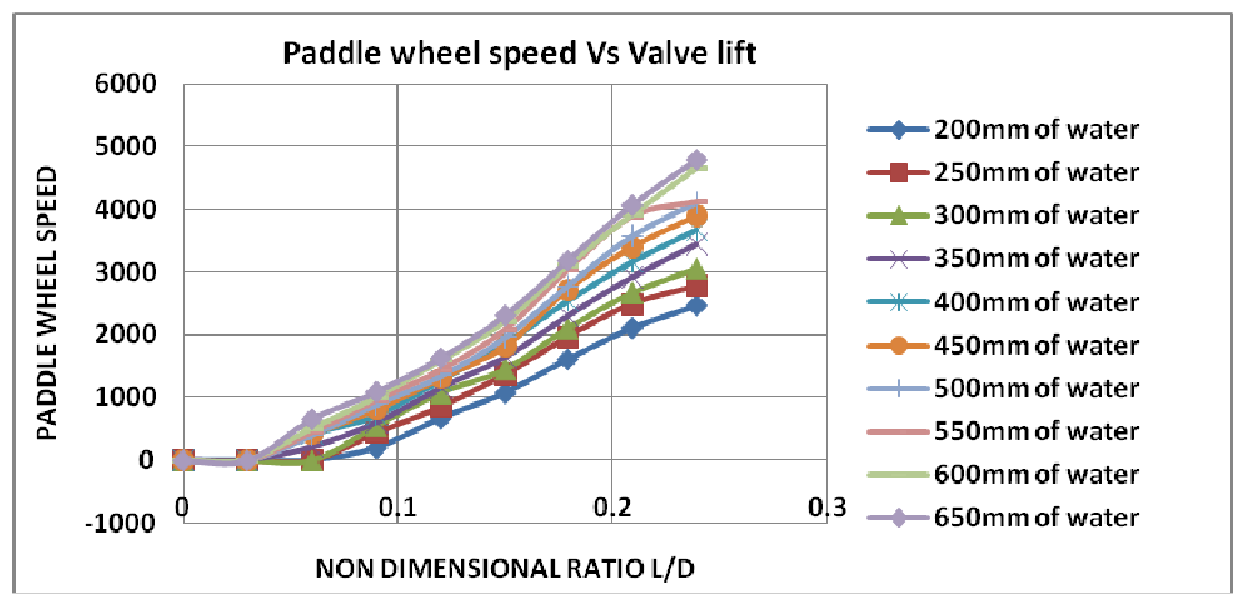

Figure 7. Paddle wheel speed Vs Valve lift ratio

The variation of the paddle wheel speed with respect to different pressures of water has been plotted in figure 7. From the above figure, it can be obsreved that the variation of paddle wheel speed with respect to non dimentional ratio L/D at different pressures are uniform and linear behaviour. Thus we can understand that with increase in pressure drop the circumferential velocity increases which increases the pedal wheel speed and it increases linearly with valve lift. 
Mechanical Engineering: An International Journal (MEIJ), Vol. 3, No. 3, August 2016

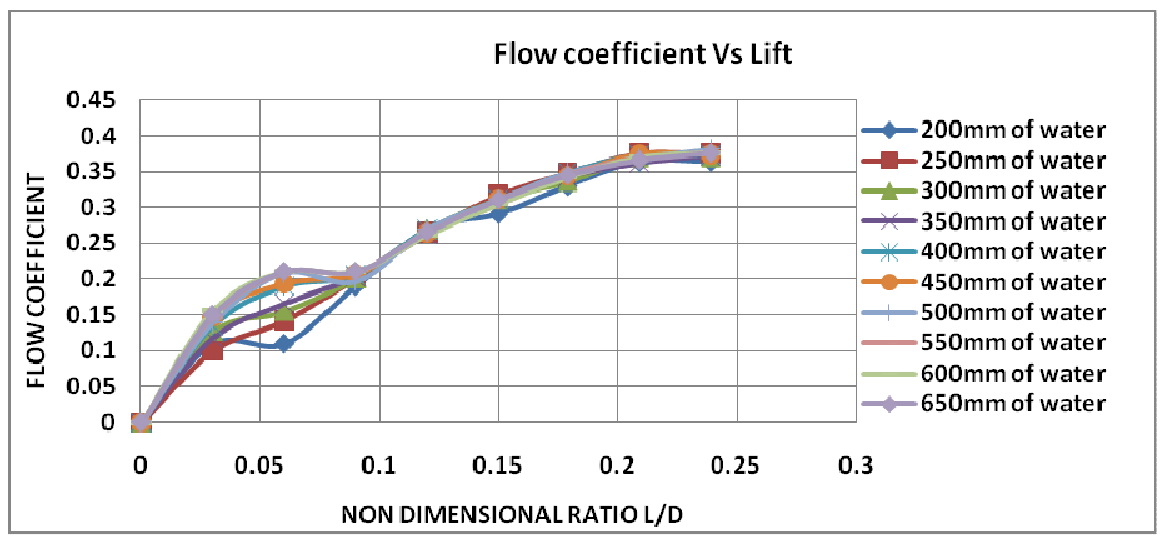

Figure 8. Flow coefficient Vs Valve lift ratio

Fig 8. shows the variation of flow coefficient versus L/D ratio. From the above figure, the variation of non dimentional ratio between 0.03-0.09 results in distortion of the flow coefficient whereas from L/D ratio of $0.10-0.22$, the flow coefficient is independent of pressure drop. Therefore in general the flow coefficient is approximately independent of pressure drop except at small valve lift, where it increases with pressure drop.

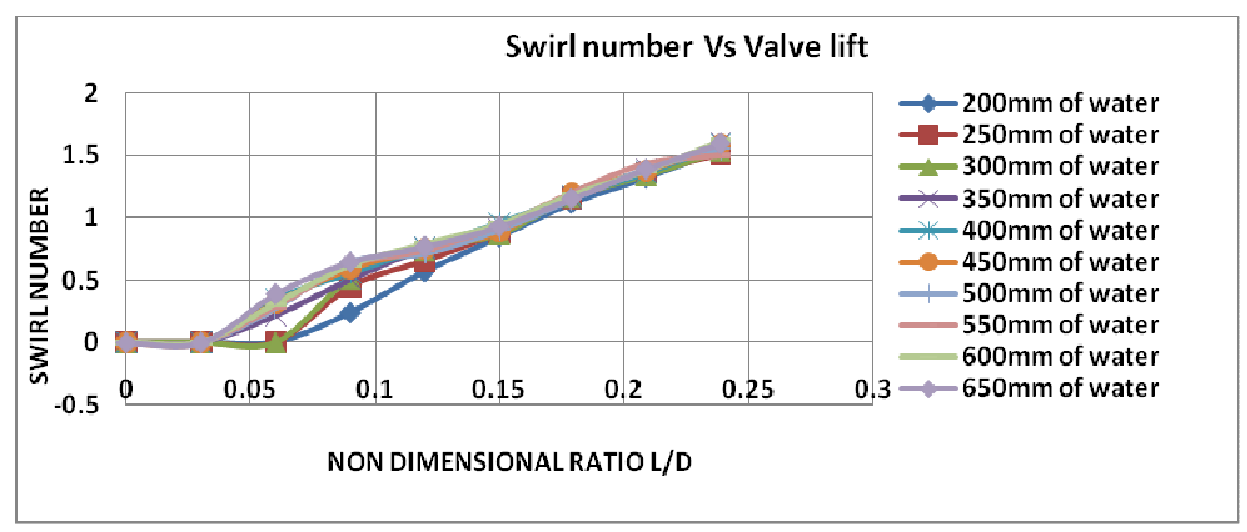

Figure 9. Swirl number Vs Valve lift ratio

The variation of the swirl number with respect to different pressures of water has been plotted in Fig. 9. From the above figure, the variation of non dimentional ratio between $0.05-0.12$ results in distorting the swirl number from 0-0.7 as disturbance is created for the flow. Thus we can understand that at lower valve lift, the swirl number increases with pressure drop but at higher lifts, the swirl number is independent of pressure drop.

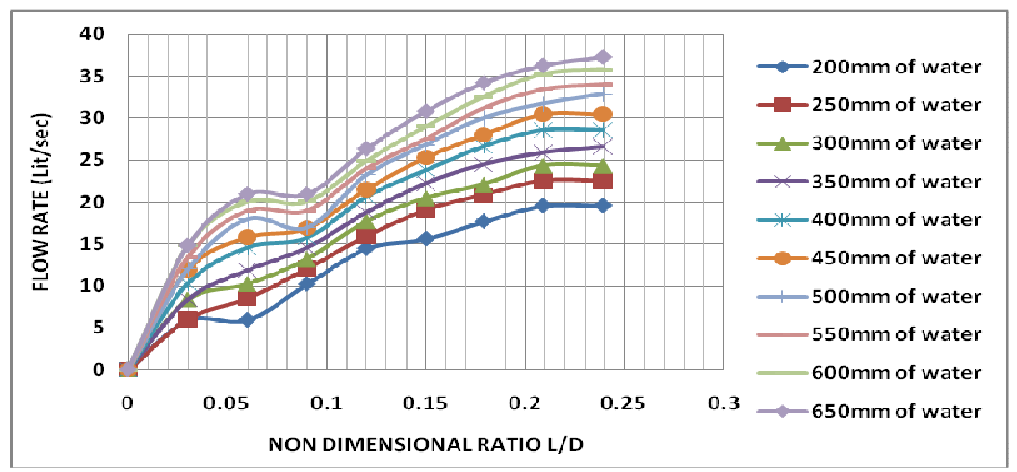

Figure 10. Flow rate Vs Valve lift ratio 
From figure 10. it may be noted that the port allows the flow from $5 \mathrm{l} / \mathrm{s}$ to $38 \mathrm{l} / \mathrm{s}$ for the L/D ratio ranging from 0.015 to 0.243 . For initial half range of $\mathrm{L} / \mathrm{D}$ ratio, the flow increases linearly and for the remaining half the increase is moderate and then it becomes asymptotic. At lower valve lift, the flow remains attached to the valve head and valve seat. But at higher lifts the flow separates from valve seat. Thus at higher valve lift, the rate of increase of flow rate decreases and becomes asymptotic.

\subsection{GRID QUALITY CHECK}

Grid quality check is carried out for aspect ratio and skewness.

\subsubsection{ASPECT RATIO}

Aspect ratio is defined as the ratio of the longest edge of an element to either its shortest edge or the shortest distance from a corner node to the opposing edge. For 3-D elements, each face of the element is treated as a 2-D element and its aspect ratio is determined. The largest aspect ratio among these faces is returned as the aspect ratio of 3-D element. . The recommended aspect ratio shall be less than 5 where in the present meshing $0.2 \%$ of the total elements are not meeting this criterion. Further efforts are on to refine local refining of the mesh.

\subsubsection{SKEWNESS}

Skew is calculated by finding the minimum angle between the vector from each node to the opposing mid-side and the vector between the two adjacent mid-sides at each node of the element. Ninety degrees minus the minimum angle found is reported as skewness of the element. The recommended skew angle shall be greater than 60 . In the present exercise $1.3 \%$ of the total elements are not meeting the criteria and efforts are on for local refining of the mesh.

\section{CONCLUSION}

The present focus is on experimental results on diesel engine inlet port and geometry acquisition and three dimensional modeling and grid generation towards CFD analysis. Quality grid is generated through three dimensional modeling. Further, computer run on high end platform is in progress. The results would be compared with experimental and calibrated CFD code would be ready for futuristic design.

\section{ACKNOWLEDGEMENT}

Authors would like to acknowledge with thanks the Christ University Management headed by Vice Chancellor, Dr. (Fr.) Thomas C Mathew, Engineering Director Fr. Benny Thomas, Associate Director (Centre for Research-Projects) Prof. D.N.S Kumar, Associate Dean, Faculty of Engineering, Dr. Iven Jose and Mechanical Department Co-Ordinator Dr. Gurumoorthy Hebbar for encouraging R \& D work. Discussions with Dr. Madhukar Rao, Technical Director, ACRI, Bangalore are acknowledged.

\section{REFERENCES}

1. Shankar. V, Experimental Studies on Seventy Two HP Class Four Cylinder Diesel Engine, Research Proposal, Report no. CUFE/MRP/001/2013, Christ University, Sep 2013.

2. D.N.S Kumar, Approval of Major Research Proposal on Experimental Studies on Seventy Two HP Class Four Cylinder Diesel Engine, Nov 2013. 
3. Ashish Jain, Ramdasi and N. V. Marathe, Port Swirl and Flow Measurement on Research Engine Cylinder Head for Christ University, Bangalore, Report No. PTE/15-16/CHRISTU/R-XXX, Feb 2016.

4. Shankar. V, "Value Added Lecture Series (VALS) on CFD ", Odd and Even semester, Mechanical Engineering Department, Faculty of Engineering, Christ University, Bangalore, Academic Year 201314.

5. Madhukar Rao, Chakrapani et.al., "Industrial CFD Course” , A Ten Month's Program (online and offline) conducted by Analytical and Computational Research Inc (ACRI), Bangalore at Christ University for research students, Academic year May 2014 to Dec 2015.

6. Ganesan, V, 'Special Lectures on IC Engines and Mathematical Modelling including physical models like turbulence, swirl and combustion", Even Semester, Mechanical Engineering Department, Christ University, Bangalore, Academic Year 2015-16.

7. S.K. Sabale and S. B. Sana, " Design and Analysis of Intake Port of diesel Engine for Target Value of Swirl, American Journal of Mechanical Engineering, Vol. 1, No. 5, 2013, pp 138-142.

8. Anqi Chen,"Application of Computational Fluid Dynamics to the Analysis of Intake Port Design in Internal Combustion Engines", A Ph.D Thesis, Loughborough University of Technology, June 1994.

9. Amann, C.A., "Classical Combustion Diagnostics for Engine Research", SAE paper no: 850395, 1985.

10. Annand, W.J.D., and Roe, G.E., "Gas flow in the internal combustion Engine, Yeovil: Foulis, 1974.

11. Mohd Taufik Bin Abd Kadir, "Intake Port Flow Study on Various Cylinder Head Using Flow bench", University Malaysia Pahang.

12. Heywood J. B., Internal Combustion Engine Fundamentals, McGraw-Hill, Inc., USA, 1988.

13. Yufeng Li., "A New Estimation of Swirl Ratio from Steady Flow Rig Testing," SAE Technical Paper 201487-01-25, 2014, doi:10.4271/2014-01-2587.

14. Shankar. V, "Experimental Studies on the Intake Port of a Diesel Engine to Determine Swirl, Paper presented in RTME Conference, Dubai, April 23-24, 2016".

15. Shankar. V, Thejaraju, R, Varun Raju, V and Amal Chacko, K., “, "Experimental Studies on the Intake Port of a Diesel Engine to Determine Swirl, Paper presented in RTME Conference, Dubai, April 2324, 2016", International Journal of Recent Advances in Mechanical Engineering, ( IJMECH), Vol. 5, No. 2, may 2016.

16. Tanaka, "Air Flow Through Suction Valve of Conical Seat", Aeronautical Research Institution report, Tokyo Imperial University, No. 50, pg: 259, 1929.

17. Kastner, L.J., William and white, "Poppet Inlet Valve Characteristics and Their Influence on the Induction process", Proceedings of Mechanical Engineering, Vol.178, pp.955-975, 1963-1964.

18. Khalighi, B.,“ Intake Generated Swirl and Tumble Motions in a 4-valve Engine with Various Intake Configurations- FVarun Ralow Visualization and Particle Tracking Velocimetry”, SAE paper $892096,1989$.

19. Shankar. V, Varunraju et.al, Intake Port Test Plan, Christ University Faculty of Engineering CUFE, Document No.: CUFE/MECH/OPI/0010

20. Amal Chacko," An Experimental Study on Intake Port Swirl Generation Using Steady Flow Test Rig", B.Tech Project Report, Christ University, March 2016.

21. Getting started with Pro/Engineer Wildfire TM 4.0, October 2007

22. CFDStudio ${ }^{\circledR}$, Grid Generation Manual, ACRI Infotech, Bangalore, 2015

23. ANSWER ${ }^{\circledR}$, Theory Manual, ACRI Infotech Pvt. Ltd., Bangalore, 2012

24. ANSWER ${ }^{\circledR}$, Keyword Command Manual, ACRI Infotech Pvtd. Ltd, Bangalore, 2014 